«Системні технологіï» 5 (136) 2021 «System technologies»

DOI 10.34185/1562-9945-5-136-2021-04

УДК 681.5.042

\title{
ОСОБЛИВОСТІ ВИКОРИСТАННЯ НЕЙРОРЕГУЛЯТОРА ДЛЯ УПРАВЛІННЯ ТЕПЛОВИМИ МЕТАЛУРГІЙНИМИ ПРОЦЕСАМИ
}

Анотація. Показані особливості використання нейрорегуляторів для управління тепловими металургійними процесами. Запропоновано спосіб інтенсифікаціі алгоритму навчання нейронної мережі.

Ключові слова: металургійні печі, управління нагрівачем, навчання нейромережі.

\section{Постановка проблеми}

Сучасні нейронні мережі (НM) широко використовуються для керування технологічними процесами. При цьому навчальні зразки є статичними, а повільна збіжність навчання НМ істотно стримує застосування НМ для задач автоматичного управління. Вдосконалення алгоритмів навчання НМ необхідно передусім для забезпечення ефективної роботи нейроконтролера в реальному масштабі часу. Але в металургійних теплотехнічних агрегатах (нагрівальні, сталеплавильні, мартенівські, конверторні печі тощо) протікають тривалі перехідні процеси, що робить такі агрегати перспективними для впровадження методів нейроуправленія.

\section{Мета роботи}

Метою роботи $є$ вдосконалення процесу навчання нейронної мережі нейрорегуляторів, що використовуються для управління тепловими процесами в металургії.

\section{Результати досліджень}

Запропоновано [2, 3] декілька методів, що прискорюють збіжність навчання НМ при використанні нейроконтролерів в технологічному управлінні.

Алгоритм, пропонований [1] для прискорення процесу навчання, грунтується на відмінності понять дискретизації процесу управління і частоти виконання навчальних ітерацій (частоти навчання).

Частота дискретизації встановлюється зазвичай відповідно до теореми Котельникова, згідно з якою вона повинна як мінімум в два рази перевищувати максимальну частоту процесу. При цьому частоту коригувань адаптивних

(C) Безуб B.M., 2021 


\section{«Системні технології» 5 (136) 2021 «System technologies»}

елементів можна прийняти один раз за кожен період дискретизації, тобто частота дискретизації і адаптації збігаються.

У багатьох практичних випадках перевищення деякого значення частоти дискретизації неприпустимо або небажано. У металургії теплофізичні процеси мають відносно велику інерцію, а високі частоти дискретизації ведуть до надмірності інформації та підвищенню вартості систем. Також збільшення частоти дискретизації може привести до прояву в системі небажаних перехідних процесів.

Пропонована ідея [1] прискорення навчання нейроконтролера полягає в тому, щоб використовуючи затримані сигнали попередніх циклів за період дискретизації провести декілька навчальних ітерацій. При навчанні мінімізується функція помилки:

$$
E(t)=\frac{1}{2}\left[\sum_{i=0}^{n-1}\left\{\left(y(t-i)-y_{i}(t-i)\right)\right]^{2}, i=\overline{0, n-1},\right.
$$

де: $\mathrm{y}(\mathrm{t})$ - поточний вихідний сигнал;

yi(t) - значення вихідного сигналу на 1-ій ітерації;

$\mathrm{n}$ - число ітерацій;

$\lambda_{\mathrm{i}}>\lambda_{\mathrm{i}+1}$ - незростаюча позитивна послідовність.

Дослідження проводилися на инверсіно-динамічній схемі нейронного управління з нейроконтролером і емулятором.

Характеристики пропонованої системи управління і методів навчання оцінювалися [1] на результатах моделювання нагрівальної печі.

Використовувалася система управління температурою нагрівальної печі [4], що описується диференціальним рівнянням

$$
\frac{d y(t)}{d t}=\frac{f(t)}{c}+\frac{c_{0} T_{c}^{o}-y(t)}{R C},
$$

де: $\mathrm{y}(\mathrm{t})$ - вихідна температура;

$\mathrm{f}(\mathrm{t})$ - кількість тепла від нагрівальних елементів;

$T_{c}^{o}$ - температура навколишнього середовища;

C - теплоємність печі;

$\mathrm{R}$ - тепловий опір кладки і футеровки печі.

При постійних C i R була отримана імпульсна перехідна функція системи, заданої рівнянням (1). Вона має вигляд: 
«Системні технологіï» 5 (136) 2021 «System technologies»

$$
y(t+l)=\alpha(\tau) y(t)+B(\tau) U(t),
$$

де: $\mathrm{t}$ - дискретний цілочисельний час;

1 - інтервал квантування;

$\mathrm{U}(\mathrm{T})$ - вхідний вплив на об'єкт;

$\mathrm{y}(\mathrm{t})$ - вихід об'єкту;

$$
\alpha(\tau)=e^{-\alpha \tau}, B(\tau)=\frac{\beta}{\alpha}\left(1-e^{-\alpha \tau}\right)
$$

$\alpha i \beta$ - константи, що характеризують $\mathrm{R} \mathrm{i} \mathrm{C.}$

При моделюванні в системі було задано насичення характеристики, щоб виключити перевищення значення вихідної температури в $1600^{\circ} \mathrm{C}$.

Модельований об'єкт описувався наступним рівнянням:

$$
y(t+l)=\alpha(\tau) y(t)+\frac{B(\tau)}{1+e^{0.5 y(t)-\gamma}} U(t)+[1-\alpha(\tau)] T_{c}^{o}
$$

Параметри

$$
\alpha=1.21 \cdot 10^{-4}, \beta=7.64 \cdot 10^{-3}, \gamma=60, T_{c}^{o}=20^{0} \mathrm{C}
$$

були отримані [1] при інверсному моделюванні мережі.

Використовувалися тришарові повнозв'язні НМ з одним вихідним нейроном, з числом вхідних нейронів відповідно кількості ітерацій за період. Число нейронів прихованого шару варіювалося від 8 до 20. Для нейроконтролера i прихованого шару нейроемулятора використовувалась сігмоїдна функція активації, а у вхідному і вихідному шарі нейромулятора - пропорційна функція $f(x)=x$.

Навчання мереж проводилося за відомим правилом з зворотним поширенням помилки $\Delta W(t)=W(t+1)-W(t)$ :

$$
\Delta W(t)=-h \frac{\partial E}{\partial W(t)}+\alpha \Delta W(t-1),
$$

де: $\mathrm{t}$ - номер ітерації навчання;

W - вага зв'язку;

Е - функція помилки (підлягає мінімізації);

$\mathrm{h}>0$ - швидкість навчання $(\mathrm{h}=0.01)$;

$\alpha \geq 0$ - миттєва складова, яка визначає осциляцію процесу ( $\alpha=0.8$ );

Початкове значення ваг нейроконтролера встановлювалося випадковим чином. 
«Системні технологіï» 5 (136) 2021 «System technologies»

Метою регулювання було підтримання температури $80^{\circ} \mathrm{C}$ для часового інтервалу $0 \leq t \leq 80$ хв., $120^{\circ} \mathrm{C}$ для інтервалу $80 x в .<t \leq 160 x 8$. і $160^{\circ} \mathrm{C}$ для інтервалу $t>160$ хв. Кожен цикл імітації вважався пробою. Після кожної проби ваги фіксувалася і робилася нова проба.

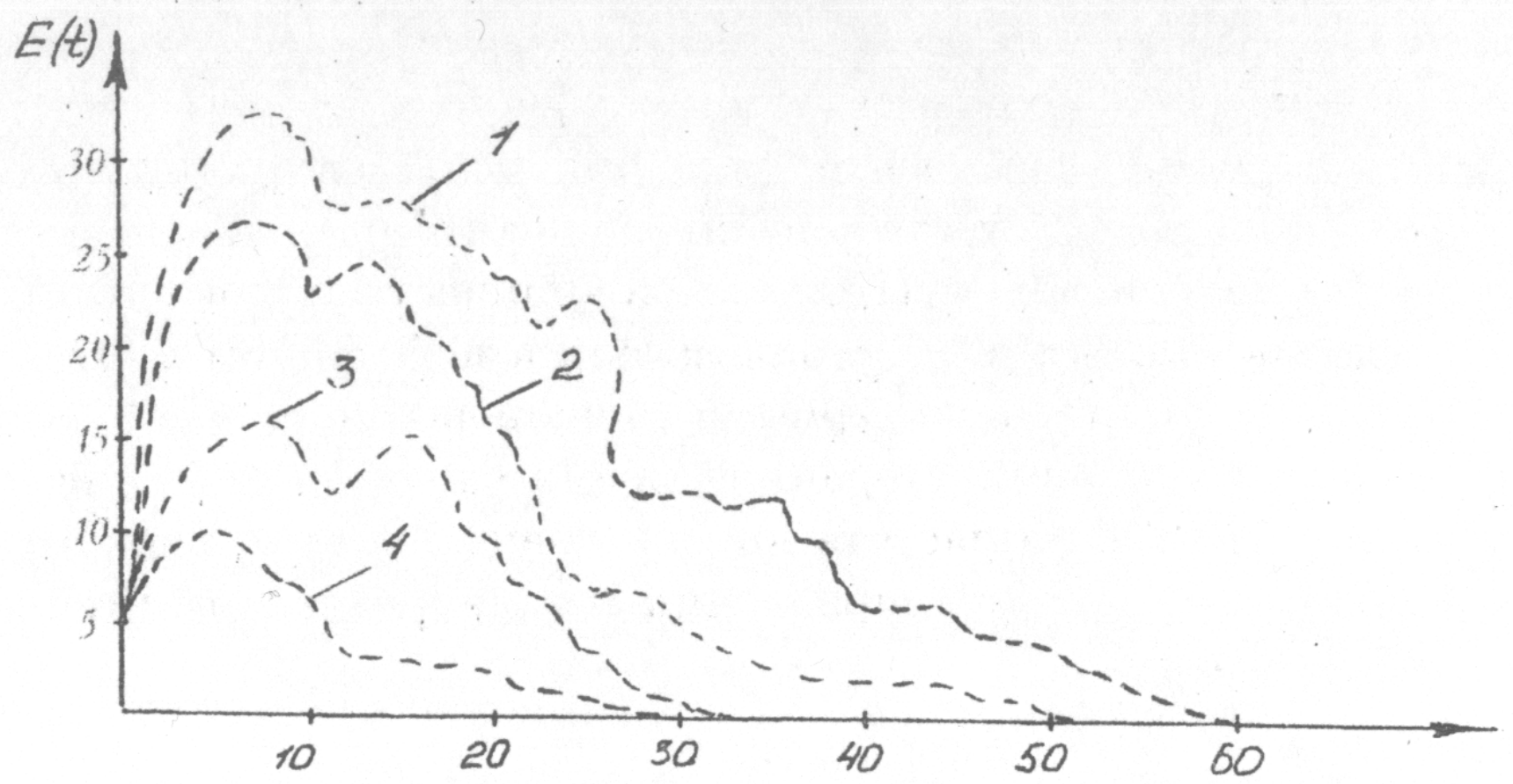

Рисунок 1 - Залежність помилки навчання НM, що виконує навчальну ітерацію від кількості проб при різних періодах дискретизації $\mathrm{T}(1-\mathrm{T}=30 \mathrm{c}, 2-\mathrm{T}=20 \mathrm{c}, 3-\mathrm{T}=10 \mathrm{c}, 4-\mathrm{T}=5 \mathrm{c})$

На рис. 1 зображено залежності швидкості навчання НМ від частоти дискретизації. Видно, що спостерігається очікуване прискорення навчання при збільшенні частоти дискретизації. При досягненні швидкості T $=10 \mathrm{c}$ i T $=5$ с швидкість навчання практично не змінюється при помітному зменшенні середньоквадратичної помилки. 
«Системні технологіï» 5 (136) 2021 «System technologies»

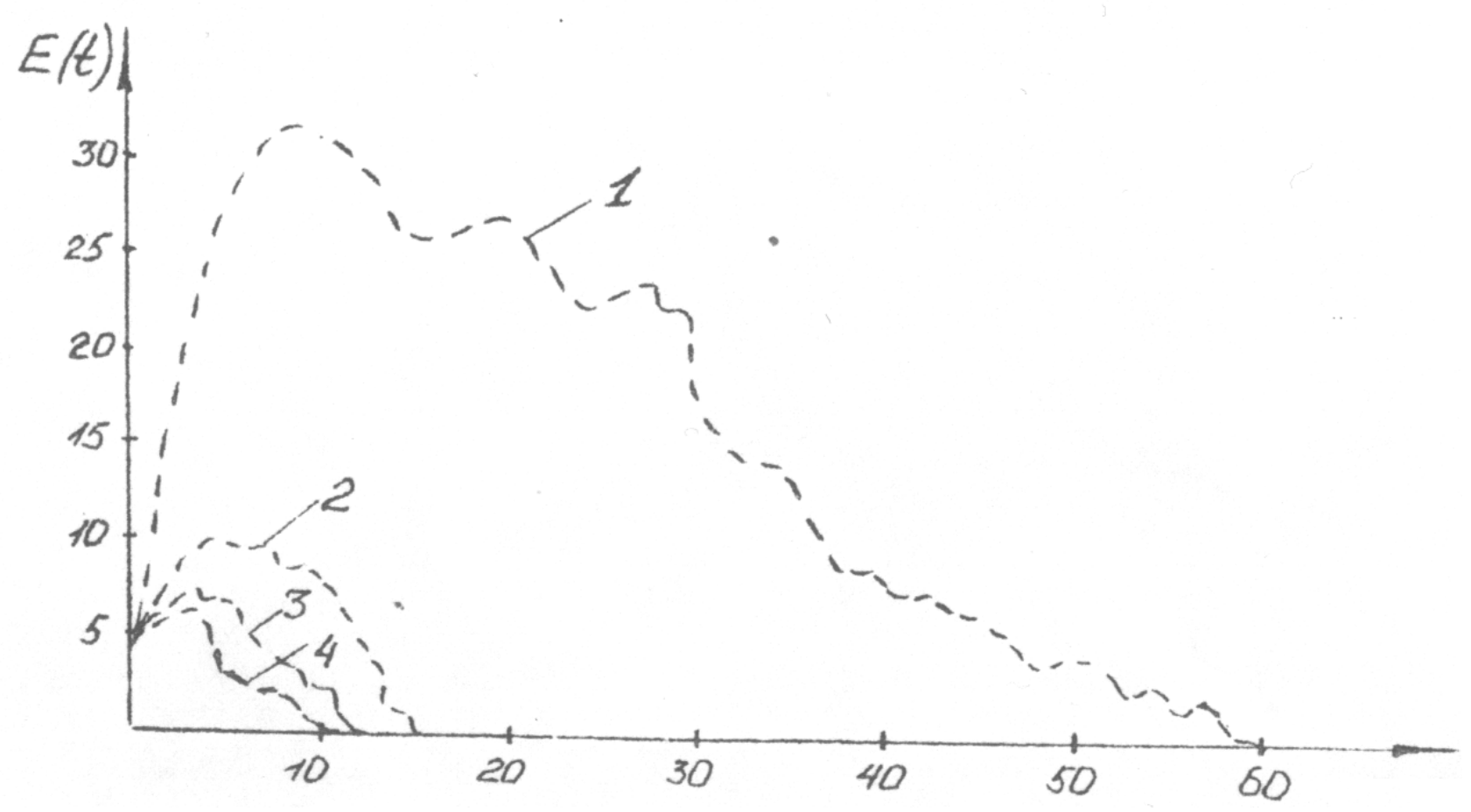

Рисунок 2 - Залежність збіжності навчання НМ при періоду дискретизації Т=30с від кількості проб (1- 1 навчальна ітерація, 2- 5 навчальних ітерацій, 3- 10 навчальних ітерацій, 4- 15 навчальних ітерацій)

На рис. 2 зображено залежність швидкості збіжності навчання НМ і величини середньоквадратичної помилки в залежності від кількості ітерацій.

3 рис.1 і рис.2 видно, що виконання декількох ітерацій навчання за період дискретизації знижує помилку і істотно покращує збіжність навчання НМ. Час навчання в першому наближенні $€$ пропорційним кількості навчаючих ітерацій. Ця кількість істотно залежить від кількості нейронів в прихованому шарі і кількості ваг в них. У наведених випробуваннях використовувалося до 20 прихованих нейронів і до 80 ваг (збільшення не поліпшило помітно характеристики). При десяти навчальних ітераціях час збіжності не перевищує 400 мс. Така частота дискретизації і тривалість навчання прийнятні для управління металургійними тепловими агрегатами.

\section{ЛИТЕРАТУРА / ЛІТРАТУРА}

1. Еременко Ю.И., Боева Л.М., Кузнецов Л.А., Крахт В.Б. Повышение АСУ горнометаллургического производства на основе интеллектуализации управления: Монография. - Старый Оскол: ООО “ТНТ”, 2005.

2. Hopfield J.J., Neural networks and physical systems with emergent computational abilities, Proc of the National Academy of Sciences, vol.79. - pp.2554-2558, 1992. 


\section{«Системні технологіï» 5 (136) 2021 «System technologies»}

3. Tanomaru J and S. Omatu Process control by on-line trained neural controllers. IEEE Trans on Indastrial Electronics, Vol.39. - pp. 511-521., 1992.

4. Глинков Г.М., Малковский В.А., АСУ ТП в черной металлургии.- М.: Металлургия, 1999. - 312 с.

\section{REFERENCES}

1. Eremenko Yu.Y., Boeva L.M., Kuznetsov L.A., Krakht V.B. Povыshenye ASU hornometallurhycheskoho proyzvodstva na osnove yntellektualyzatsyy upravlenyia: Monohrafyia. - Starbi Oskol: OOO “TNT”, 2005.

2. Hopfield J.J., Neural networks and physical systems with emergent computational abilities, Proc of the National Academy of Sciences, vol.79. - pp.2554-2558, 1992.

3. Tanomaru J and S. Omatu Process control by on-line trained neural controllers. IEEE Trans on Indastrial Electronics, Vol.39. - pp. 511-521., 1992.

4. Hlynkov H.M., Malkovskyi V.A., ASU TP v chernoi metallurhyy.- M.: Metallurhyia, 1999. - $312 \mathrm{~s}$.

Received 21.03.2021. Accepted 26.03.2021.

\section{Особливості використання нейрорегулятора}

\section{для управління тепловими металургійними процесами}

Аналіз стану і тенденцій розвитку управління в металургії показує, що подальще вдосконалення систем управління (Су) на основі класичного підходу вимагає підвищення адекватності математичних моделей процесу, що наштовхується на труднощі, наступні з обмеженою можливості пізнання фізико-математичних процесів $і$ багатьох випадкових факторів, що впливають на їх розвиток. у цих умовах методи інтелектуального управління (нечітке управління, нейроуправління, використання експертних систем) дозволяють вирішувати широкий клас задач керування об'єктами $і$ прочесами гірничо-металургійного виробництва, що важко формалізуються. Досить ефективним виявляється раціональне поєднання різних методів інтелектуального управління.

В результаті досліджень, виконаних на моделях теплових агрегатів гірничометалургійного виробництва встановлена можливість і ефективність застосування для них нечіткого керування, що забезпечує подальше підвищення продуктивності агрегатів та якості продукції.

\section{Features of using neuroregulator to control thermal metallurgical processes}

Analysis of the state and trends of management development in metallurgy shows that further improvement of control systems $(B C)$ based on the classical approach requires an increase in the adequacy of mathematical models of the process, which encounters difficulties that follow with the limited ability to know physical and mathematical processes and many random factors that affect their development. Under these conditions, intelligent control 


\section{«Системні технологіï» 5 (136) 2021 «System technologies»}

methods (fuzzy control, neuromanagement, the use of expert systems) allow solving a wide class of object management tasks and difficult-to-formalize mining and metallurgical production processes. A rational combination of different methods of intellectual management is quite effective.

As a result of studies carried out on models of thermal units of mining and metallurgical production, the possibility and efficiency of using fuzzy control for them was established, which ensures a further increase in the productivity of units and product quality.

Безуб Володимир Миколайович - ст.викладач кафедри Інформаційних технологій та систем, Національна металургійна академія України.

Безуб Владимир Николаевич - ст. преподаватель кафедры Информацыионных технологий и сисем, Национальная металлургическая академия Украины.

Bezub Vladimir - The National Metallurgical Academy of Ukraine. 